\title{
Spread of alimentary-toxic paroxysmal myoglobinuria-haff disease (literature review)
}

\author{
L.A. Glazunova*, A.R. Musina, A.A. Yurchenko, Y.V. Glazunov, and E.M. Gagarin
}

Federal State Budgetary Educational Institution of Higher Education Northern Trans-Ural State Agricultural University, Tyumen, Russia

\begin{abstract}
In 1924, Haff disease was first detected in East Prussia. Till now, cases of Haff disease have been recorded in Sweden, Russia, the United States, China, Brazil, Japan, and China among people and animals. During the last 40 years, there has been a significant expansion in the geographical range of Haff disease. From 1924 to 2019, 31 outbreaks were recorded in various parts of the world. The total number of victims was about 3,000 people. In Russia, the last cases of human disease were registered in 20192020. In fact, the source of the toxin is fish (crucian carp, carp, pike, burbot, walleye, perch, ruff, ide, yellowtail, black sea bass, eel, silver dollar, brown paku, red paku, cowfish, etc.) or crayfish. Today, the problem of the disease etiology has not been solved; the toxin with the corresponding features has not been isolated, and as a result, causal and pathogenetic treatment of alimentary-toxic paroxysmal myoglobinuria has not been developed. Over this period, several hypotheses were made that are leading in the study of the etiology of the occurrence of Haff disease (thiaminase theory, tannic, arachidonic). This disease-causing substance is known to be heat-resistant and break down the metabolism of skeletal muscles, resulting in the release of myoglobin, which disorders kidney function. It has also been found that toxic substances themselves gradually resolve from the fish, according to its diet (depending on what prevails - plankton, zooplankton or larvae, mollusks, crustaceans). For finding out the origin of the disease, it is essential to conduct comprehensive research by biologists, hydrologists, doctors, and veterinarians.
\end{abstract}

\section{Introduction}

Haff disease or alimentary-toxic paroxysmal myoglobinuria (ATPM) is an acute rare disease of uncertain etiology occurring sporadically among fish (crucian carp, carp, pike, burbot, walleye, perch, ruff, ide, etc.), some carnivorous animals, birds, and human beings. This disease emergences from the consumption of fish that have gained toxic properties during their life in the reservoir. This disease is expressed by dystrophic changes in the cells of both the spinal cord and brain, striated muscle fibers and the epithelium of the convoluted tubules of the kidneys.

\footnotetext{
* Corresponding author: glazunovala@gausz.ru
} 


\section{Results and discussion}

Firstly, this disease was identified in the summer and autumn of 1924 in the population (mainly among fishermen) who consumed fish (pike, eel, walleye, etc.) from the Frisches Haff Bay of the Baltic Sea (East Prussia, now the Vistula Lagoon in the Kaliningrad region of the Russian Federation). The location of the first outbreak and registration has given the name of the disease - Haff (from the German word Haff which means "bay"). During the following years, only a few cases were recorded in the same region, in 1932-1933 and in 1940. It is estimated that more than 1,000 cases have been reported during these epidemics, including 18 deaths $(1.6 \%)$. Epidemiological studies have revealed that patients with Haff disease ate boiled fish, including pike, eel, and walleye, within 24 hours before the onset of the disease.

Similarly, on the shore of the Haff Bay, an extraordinarily high mortality rate among fish was recorded, as well as dead foxes and coastal birds were found along the shores. Cats in fishing villages died or developed posterior paralysis after eating fish.

Originally, it was supposed that the disease was related to the ingress of industrial waste water, in particular waste from the production of cellulose, and poisoning by the products of biotransformation of tar acids. It was also proposed that the infectious and allergic nature of the disease, but experimentally, this was not verified, however, and a specific toxic substance, and consequently, the causes of the disease were not identified [1].

Further outbreaks similar to Haff disease have been reported in Sweden, Russia, the United States, China, Brazil, and Japan.

In February 1942, an outbreak of Haff disease was noted on the Imsen Lake in Sweden. 11 people then had bouts of severe muscle pain, and a change in the color of their urine to a blackish-brown color. In each case, the patients ate fish a few days before they became ill. In most cases, it was an eel or burbot. In early April 1943, there was another case of poisoning similar to the symptoms of Haff disease. The patient was a 22 -year-old girl who ate burbot liver from Imsen Lake [2].

Like in the case of the Frisches Haff Bay, and on the Swedish lake, a similar disease affected the animals. Within the epidemic, the mortality rate among fish in the lake increased, and birds, whose diet mainly consisted of fish, also died in great numbers. The birds lay on the bank and crawled. They could not go up, flapped their wings weakly, lay with their beaks wide open. Additionally, many cats died after eating fish caught from the lake. Many of them suffered from palsy of the hind limbs. Equally on a fox farm near the lake, where the animals were fed mainly fish, there were several sudden deaths among foxes. Eyewitnesses reported that the foxes were dizzy before they died and behaved as if they had dizziness.

The silt, plants, water, and fish from the lake were subjected to biological and chemical analysis, but the experiments did not detect any abnormalities.

Besides, the suggestion that the disease may have an allergic origin was discussed. Burbot liver extracts were made for intradermal administration to patients who had suffered from this disease. Yet these experiments had a negative result.

Further investigation into the causes of Haff disease at Imsen Lake suggested that the symptoms of this disease have a similar relationship to the disease known as ChastekParalyse, which was first seen in America on silver fox farms. This disease occurs in furbearing animals after they eat raw fish. The clinical picture is expressed in loss of appetite, apathy. The animals, curled up, lie on the floor and do not move. While moving, foxes steadily walk in a circle in one direction. Over time, the animals begin to tremble and there are muscle cramps. Chastek-Paralyse is marked by a deficiency of vitamin B1 in fur-bearing animals, caused by feeding them raw fish containing a large amount of thiaminase, which breaks down vitamin B1, that subsequently leads to its deficiency, and the occurrence of such symptoms as: limbs paralysis, convulsions, unsteady gait with a crooked back and 
inconsistency of movements. This clinical picture was quite similar to the case at the fox farm near Imsen Lake. Since Chastek-Paralyse was caused by a deficiency of vitamin B1 (thiamine), the researchers presume that the same reason could cause Haff disease, but this theory has not been confirmed due to the fact that it was raised only after the last case occurred, and therapeutic tests could not be performed $[3,4,5]$.

In the USSR, the first outbreak of Haff disease occurred in 1934. It was related to the consumption of boiled, fried, dried fish (pike, perch, ruff, walleye, burbot) and was observed among the population of the village of Yuksovichi and other villages on the coast of Yuksovskoye Lake. It occurred suddenly, with bouts of muscle pain and, in exceptional cases, ended in death as a result of damage to the diaphragm and respiratory muscles. The disease was quickly localized due to the prohibition of fishing and by buying fish from the population caught from the lake. Totally 400 people were ill at that time, eight of them died ( $2 \%)$. Out of 142 cats, $120(91 \%)$ died [6].

First observations of epidemiologists have demonstrated that the disease is caused by the consumption of 5-6-month-old young perch. They traced the food chain: plankton-young perch-predatory fish species (pike, walleye, burbot, perch, ruff) - humans. The most toxic were the internal organs of predatory fish: intestines, liver, fat, caviar and milt. Bream, ide and roach were practically safe.

Leningrad Regional Health Department performed a comprehensive expedition to study the Yuksov disease. Bacteriologists and epidemiologists from Pasteur Institute, pathologists from the Institute of Experimental Medicine, employees of the Veterinary Institute, hydrobiologists, ichthyologists and hydrochemists from the Institute of Fisheries were invited to take part in the investigation.

For two and a half years, the expedition worked in the field (Yuksovichi) and in laboratories. The toxic substance accumulated in the fish was isolated from dried fish. It was heat-resistant. The toxic substance impairs the metabolism of skeletal muscles. As a result, myoglobin is released, which disorders the function of the kidneys. Myoglobin is similar to hemoglobin: it provides a continuous delivery of oxygen to the working muscles. Thus, its deficiency affects the patient's condition so depressingly with increased physical exertion and cooling of the body.

Infectious-bacterial, viral, and parasitic causes of Yuxov disease were rejected. It was supposed that the fish primarily gets toxicity by feeding on plankton infected with toxic substances washed out of the ground. As there was no discharge of waste water into Yuksovskoye Lake, the hypothesis of the connection of Haff-Yuksov disease with toxic substances as a result of industrial pollution disappeared [7].

Research has revealed and explained a lot. For example, it appeared that the toxic substances themselves gradually faded from the fish in accordance with its diet (depending on what prevails - plankton, zooplankton or larvae, mollusks, crustaceans). There was also a fact: long-term storage of dried fish deprives it of toxicity. The dried perch seized from the people after six months of storage in the warehouse became harmless and did not lose its nutritional properties.

Nevertheless, the toxin accumulating in fish in its pure form has not been isolated. Its chemical composition and structure have not been determined, and the action mechanism on the human body has not been sufficiently studied. The source of the toxin in the water and the way it passes into the fish was not discovered.

In late 1934, outbreaks stopped. In 1935, only isolated cases were reported. However, the ban on the sale and fishing of fish from the lake was kept for two years [8].

In 1947-1948 and in 1984, an outbreak of Haff disease was detected in the Novosibirsk region near the coast of Lake Sartlan. It was determined that the dead people and animals ate fish (perch) from Lake Sartlan. Within three days, the patients had typical signs of food poisoning. After that, convulsions began, and eventually renal and liver failure developed. 
As a result, 120 people fell ill, six died. After the outbreak of such a disease on Lake Sartlan, another name for it appeared - Sartlan disease [9, 10,11].

On the basis of the general clinical symptoms of Haff-Yuxov-Sartlan disease, it was suggested to replace this "geographical" name with one of two medical variants: alimentarytoxic paroxysmal neuromyodystrophy or alimentary-toxic paroxysmal myoglobinuria (ATPM). In medical and biological practice, the second name (ATPM) has become common, emphasizing food poisoning (alimentary-toxic), seizure-like nature in the form of spasms (paroxysmal) and the presence of muscle proteins in the excretory system (myoglobinuria) $[12,13,14]$.

Besides already mentioned sites (Frisches Haff Bay, Yuxov Lake, Imsen Lake, Sartlan Lake), there were outbreaks of ATPM among the population about the following bodies of water: Ushkozero Lake (Karelia) with 2 deaths in 1947; channel pond in the Kharkiv region of Ukraine in 1960; Chernoprudinsk reservoirs in the Zhytomyr region of Ukraine in 1964; Bolshoe Ostrovnoe Lake situated in Mamontovskiy district of the Altai territory in 1975; Ubinskoe Lake in Novosibirsk in 1984; lakes and channels of Tamansky groups of eponymous drainage systems in the Tyumen region in 2000- 2001. Totally, 1,959 people became ill, including 39-with a fatal outcome ( 2\%). Data on ATPM in the USSR in some cases were performed on a closed down topic.

In 1984, the first case of Haff disease was recorded in the United States. The first two cases were find in Texas (June 1984), followed by two in Los Angeles (1985) and two in San Francisco, California (April 1986). Each of these cases occurred after eating bigmouth buffalo fish. The bigmouth buffalo fish is a bottom-dwelling freshwater fish similar to the carp [15].

In 1997, six cases of Haff disease were registered in the United States (four in California (Los Angeles) and two in Missouri (St. Louis)).

The cause of poisoning was bigmouth buffalo fish (fried, chopped as part of the dish). The Los Angeles victims bought the fish from a Louisiana wholesaler, who bought the fish from local fishermen. He caught it in various rivers in Louisiana. The fish that people ate in Missouri was caught by them 100 miles from St. Louis.

In September 2001, there was another case of poisoning similar to Haff disease. A married couple from the city of Oriental, North Carolina, ate baked salmon for dinner. The salmon was purchased in the city of New Bern at a local supermarket. After dinner, the couple felt well, but on the morning of the next day they had weakness, and severe pain in the muscles of the whole body. After 20 days of treatment, all of the above symptoms disappeared, and no relapses or recurrences were observed during the three years of follow-up [16].

All manifestations of Haff disease in the United States are related to the consumption of fish purchased in shopping centers, including those from other states. Therefore, the reservoir and the place of fish production were very rarely resolved [15].

While in Russia, focal outbreaks with dozens and hundreds of diseases are registered, in the United States, as a rule, data from individual cases of patients suffering from Haff disease are published in medical journals. Consequently, the publications contain more information concerning the symptoms and personalities of the patients, less about the treatment of the disease, and very little about its etiology. Therefore, the toxin that caused Haff disease in the United States has not been determined.

From May 8 to June 18, 2000, in the village of Narimanovo and the settlement of Novotormansky, cases of diseases of people, as well as dogs and cats, with pronounced signs of toxicosis, began to be registered in Russia's Tyumen region. For that period, a total of 28 cases of ATPM were registered, 20-in the rural population, and 8 people from Tyumen. Similarly, in 2001, 3 more cases of the disease were reported. 2 people were from the settlement of Narimanovo and one person from the settlement of Molchanovo. The Tyumen veterinary center registered 43 cases of cat disease with a pronounced clinical picture of 
ATPM. Toxicosis in most cases occurred due to feeding the animals with carp purchased from local residents.

According to the research of VNIIVEA, in 2000, the presence of toxins in fish causing Haff disease was found using the cat bioprobe method. It was established that crucian carp from the lakes of the Tarman group were toxic: Sredneye Tarmanskoe, Bolshoe Tarmanskoe, and Shaitanskoe [17].

During repeated bioassay in the second and third quarters of 2001, the following lakes remained positive for ATPM: Sredneye Tarmanskoe, Bolshoe Tarmanskoe, and Shaitanskoe.

In October-December, 2001 in the study of fish from the lakes Srednyye Tarmanskoe and Bolshoe Tarmanskoe, a negative result was received for ATPM.

In the second and third quarters of 2002, positive results of the bioassay were obtained for carp from the following lakes: Bolshoe Tarmanskoe, Kopanets, Sredneye Tarmanskoe, and Shaitanskoe [17].

While conducting a number of studies from 2000 to 2002, the toxin was not isolated, but many discoveries were made, for example, it was found that the source of the toxin in the lakes of the Tarman group was water horsetail - as a natural source of thiaminase-like compounds, which are enzyme antagonists of vitamin B1. A laboratory model of ATPM was carried out using water horsetail and the picture of toxicosis in laboratory mice was described when they were fed horsetail detritus. The clinical picture of toxicosis in laboratory mice during the use of water horsetail was identical to the clinical picture that occurs in ATPM $[18,19,20]$.

The first cases of ATPM in Japan dated back to 1992, when for the first time a case of fish poisoning (cow fish) was recorded with the occurrence of myoglobinuria and rhabdominolysis in humans, typical for Haff disease [21].

In 2007, a second case of cow fish poisoning was reported. The victim was a 40 -year-old man, a fisherman. At the end of August 2007, at 7 o'clock in the morning, he returned home after fishing and cooked a cow fish, which he caught with a net. All the organs except the liver were extracted, and the fillets and liver were grilled and eaten for breakfast. In the evening of this day, the man felt ill. Myalgia developed from the shoulders to the forearms, and a little later, shortness of breath and chest pressure were added to the symptoms, after which he was hospitalized [22].

In June 2008, in Brazil, a 39-year-old female doctor was admitted to the Emergency department of a public hospital in Manaus, Amazonas State, Brazil, with diffuse myalgia and chest pain. There were no classic risk factors for rhabdomyolysis in the anamnesis. Her mother had been hospitalized a week earlier with the same symptoms. Both women reported eating fish 24 hours before the onset of symptoms.

Twenty-five cases of Haff disease were identified in Manaus between June and September 2008. All the victims said that they had consumed fried fish (silver dollar, brown pacu, red pacu) within 24 hours prior to the onset of symptoms. All three types of fish were caught in the Amazon River [23].

All patients were admitted to hospital (range: 3-6 days) with sudden onset of myalgia. Nineteen patients have reported chest pain, among other symptoms. No fever or renal damage was observed. There were no deaths.

In just 4 months, 27 cases of Haff disease were reported in Manaus and the surrounding townships. The diagnosis of Haff disease was made on the basis that none of the cases could be explained by the classic causes of rhabdomyolysis. All patients reported fish consumption within 24 hours before the onset of symptoms. It should also be noted that there were no repeated cases of poisoning after the start of the fishing ban period in the region [23].

In Buryatia, Haff disease was first reported in July 2008 among residents of the villages of Istok, Yartsy, Cheryomushki, and Kotokel, located near Kotokelskoye Lake. There were 18 cases of Haff disease (13-in the summer of 2008, 1-in January 2009, 4-in following 2010- 
2011), mainly related to the consumption of bream caught in Kotokelskoe Lake and the Turka River. The clinical picture developed 18-24 hours after eating fish caught in Kotokelskoye Lake, despite the heat therapy (in fish broth, fried, salted or smoked). The clinical manifestations of most of the victims are the same: weakness, malaise, headache, decreased urination, darkening of urine, muscle pain, mainly in the extremities and lower back, difficulty breathing, sweating, fever. Analysis of patients revealed: changes in the color of urine (dark, red-brown, brown), short-term polyuria, followed by oliguria, pronounced proteinuria, granular and hyaline cylinders, increased levels of white blood cells in the urine, in some cases microhematuria. A single case of Haff disease was fatal.

In all the analyzed case histories, there were no paroxysms (attacks) of myoglobinuria, which is a distinguishing feature of the disease in Buryatia from cases of ATPM in other regions. Generally, the disease was classified as myoglobinuric acute renal failure on the background of rhabdomyolysis (destruction of skeletal muscles), the clinical signs of which are similar to alimentary-toxic paroxysmal myoglobinuria (ATPM, Haff disease).

While conducting laboratory studies, the thiaminase hypothesis was examined, i.e., due to the large amount of thiaminase in fish and in coastal horsetail, it could cause B1 deficiency, the clinical manifestations of which are similar to the ones of Haff disease. However, in experimental studies conducted in 2009, the thiaminase hypothesis for the Kotokel outbreak was not confirmed: horsetail collected in the coastal zone of the lake (fresh and detritus) did not cause the development of ATPM in laboratory animals. Myoglobinuria was observed in a group of animals that had been receiving concentrated water from the lake for a long time. It is clear that the toxicant that causes the fish damage was in the water, but it was not possible to identify it $[24,25]$.

In 2011, a second case of fish poisoning occurred in Manaus, Brazil. The clinical picture of poisoning was similar to Haff disease. The victim was a 48-year-old man. Man said that about 2 hours after eating a meal containing Milossoma silverfish, he felt sudden, progressive, diffuse, and piercing abdominal pain, followed by two episodes of vomiting, progressive polymyalgia (mainly in the lower extremities), asthenia, and progressive muscle weakness. Notably, in men, the level of myoglobin (a marker of the acute phase of muscle damage) reduced gradually. There was an abrupt and transient increase in the total level of creatine phosphokinase (CPK), followed by a gradual decline, which is characteristic of rhabdomyolysis, which occurs in Haff disease. On the 8th day after admission to the hospital, he was discharged. The disease symptoms were no longer noticed, and the markers of muscle damage were within normal ranges [26].

In 2014, 13 years later, a second case of ATPM-related poisoning was reported in the United States. A 48-year-old man went to the emergency room because of the unexpected occurrence of acute muscle pain, especially in the legs, chest and back. The symptoms worsened when he returned home from work. He denied having a fever, taking new medications, using drugs, heavy physical exertion, and injuries. Like in other similar cases, the CPK level was many times higher than normal, and myoglobin was also significantly increased. The diagnosis of rhabdomyolysis was made, but the etiology was unknown. The acute attack of muscle pain lasted for 10-12 hours, and then passed. CPK and myoglobin started to improve on day 4. Later, the man said that, the day before, he had eaten soup made from buffalo fish, which he had bought in a local retail chain [27].

An unusually large outbreak of ATPM was reported in El Salvador, Brazil, in December 2016. During the whole month, 12 cases of poisoning related to the use of fish were detected. In the clinical picture, the poisoning was similar to the manifestation of Haff disease. In January 2017, three more cases were diagnosed. After the occurrence of repeated cases of poisoning, local health agencies began an active search for the sick and search for similar cases. Up to April, another 52 cases of ATPM-like poisoning were registered. All patients stated that they had consumed fish (yellowtail, black sea bass) a few days before the onset of 
the disease. Laboratory tests failed to isolate the toxin. Later, and to date, no repeated outbreaks have been recorded in Brazil [28].

In China, Haff disease was first registered in Beijing in 2000, when 6 people were touched, who ate boiled crayfish 24 hours before the occurrence of clinical signs [29]. In the future, the outbreak was repeated in 2009, and occurred annually until 2017 . Over this period, 1008 cases of ATPM were recorded in humans. All cases were related to the consumption of crayfish. Outbreaks were recorded in Beijing, Hong Kong, and Shanghai.

Laboratory tests carried out in China between 2009 and 2017 also did not identify a specific toxin that causes ATPM [1, 14, 16, 30, 31, 32, 33, 34, 35, 36, 37, 38, 39, 40,41].

The most recent cases of Haff disease were registered in 2019-2020 in Russia in the Tyumen region, where sick people were found in October 2019 with a clinical performance of toxicosis, who used fish caught in Andreevsky Lake in the Tobolsk district. Four biological tests were performed on four mice, three of which showed the existence of the toxin in the caught fish.

\section{Conclusion}

Haff disease cases are regularly reported in many countries all over the world. It is known that the origin of the toxin is fish, and the main clinical implications of the diseases have also been recorded. Today, the etiology problem of the disease has not been solved. The toxin with the relevant features has not been isolated, and as a result, the etiotropic and pathogenetic treatment of alimentary-toxic paroxysmal myoglobinuria has not been developed. For solving the problem of the disease's origin requires integrated research by biologists, hydrologists, doctors, and veterinarians.

\section{References}

1. Ch. Nengwu, Ch. Cheng, J. Int. Med., 5, 429 (2017)

2. A.A. Shalaev, Hyg. \& San., 9, 47 (1946)

3. G.G. Vinberg, Usp. Sovr. Biol., 38, 216 (1954)

4. E.N. Orlov, D.B. Gelashvili, A.K. Ibragimov, Poisonous plants and animals in the USSR, 272 (1990)

5. R. Berlin, Acta. Med. Scand., 129, 560 (1948)

6. V.E. Laskin, Sovetsk. vrach. Zhurn, 9 (1939)

7. V.E. Laskin, Hyg. \& San., 10, 44 (1948)

8. V. Prokacheva, Zh. Nauk. i zh., 7, 36 (2009)

9. Yu. Z. Berman, A.V. Strusevich, Papers of the Novosibirsk State Medical Institute and the Barabinsk Department of VNIORH, 118 (1957)

10. Report of the Novosibirsk Institute of Bioorganic Chemistry of the USSR Academy of Sciences, on the chemical study of the peliadi toxin, which caused Haff (Yuksov, Sartlan) disease in 1984, 36 (1986)

11. I.N. Kozlov, G.L. Konovalov, Hyg. \& San., 7 (1951)

12. T.I. Birger, A.Ya. Malyarevskaya, O.M. Arsan, Gidrobiol. zh., 9.1, 115 (1973)

13. F. Dörbeck, Klin Wochenschr, 5, 799 (1926)

14. Z. Jie, Y. Juan, M. Qingyi, Cl. Misd. \& Mist., 5, 39 (2014)

15. Centers for Disease C Prevention, Haff disease associated with eating buffalo fish, 47, 1091 (1997) 
16. X. Huang, Y. Li, Q. Huang, BMC Pub. H., 13, 447 (2013)

17. G.S. Sivkova, Alimentary-toxic paroxysmal myoglobinuria (ATPM)/, (Methodological guidelines, Tyumen State Agricultural Academy, Tyumen, 58, 2004)

18. S.N. Gashev, N.V. Turbasova, Akt. probl. medit. i biol., 2, 156 (2003)

19. I.L. Gusygin, Toxicology of poisonous plants, 624 (1962)

20. D.A. Razmashkin, A.A. Babushkin, T.S. Mitrofanova, Abstracts of the 8th Congress of the Hydrobiological Society, 2, 166 (2001)

21. T. Shinzato, A. Furusu, T. Nishino., Intern Med, 47, 853 (2008)

22. S. Taniyama, T. Sagara, S. Nishio. Sh. Eis. Zasshi, 50, 270 (2009)

23. M.C. dos Santos, B.C. de Albuquerque, R.C. Pinto, Rev. Panam. Salud. Publica, 26, 469 (2009)

24. V.V. Fedorov, L.I. Komissarova, Methodological guide for veterinarians of the Faculty of Advanced Training, 32 (1991)

25. N.N. Smirnov, O.I. Feoktistova, Proceedings of the Institute of Water Reservoir Biology, 5(8), 10 (1963)

26. O. Tolesani jr., C. N. Roderjan, E. do Carmo Neto, Rev. Bras. Ter. Intensiva, 25, 348 (2013)

27. J.V. Louis, S. Sein, C. Lyon, J. Investig. Med. High Impact Case Rep., 4(3) (2016)

28. A.C. Bandeira, G.S. Campos, G.S. Ribeiro, Euro Surveill., 22(24) (2017)

29. Y. Yuan, Q. Chen, Chin J. Neurol., 6, 343 (2001)

30. X. Chen, P. Huang, J. Kang, Chin Emergency Med., 10, 1062 (2010)

31. X. Chen, P. Huang, J. Zhang, Chin J. Emergency Med., 12, 1141 (2016)

32. G. Feng, Q. Luo, P. Zhuang, Rev. Bras. Ter. Intensiva, 26, 407 (2014)

33. L. Gan, Q. Li, N. Gong, J. Liaoning Med. College, 3, 111

34. L. Han, J. Zhang, Int. Med., 5 (2011)

35. X. Li, H. Li, S. Li, Shanghai Prev. Med., 6, 498 (2017)

36. W. Tong, G. Yin, Nurs. Prac. \& Res. 19, 157 (2011)

37. P. Xie, J. Hu, J.M. Huang, Hell. J. Nucl. Med., 16, 60 (2013)

38. B. Yuan, G. Wu, B. Guo, Jian. Prev. Med., 4, 43 (2013)

39. Z. Wenqi, C. Shizhen, L. Jinfeng, Jiangsu Prev. Med., 2, 227 (2016)

40. R.L. Langley, W.H. Bobbitt. South Med. J., 100, 1147

41. Y.V. Glazunov, L.A. Glazunova, Ind. Vet. J. 95(1), 219 (2018) 